\title{
The nexus between governance factors and foreign di- rect investments: Evidence from panel data
}

\author{
Zekeriya Mizirak ${ }^{1}$, Kivanç Altintaş ${ }^{2 *}$ \\ 1, 2 Faculty of Political Sciences, Necmettin Erbakan University, Konya, Turkey
}

\section{Keywords \\ Foreign direct investments Governance factors \\ Panel data analysis \\ Macroeconomic variables UNCTAD}

Received: 13 October 2017

Accepted: 20 December 2017

Published: 13 February 2018

\begin{abstract}
In recent years, Foreign Direct Investments (FDI) has been a vastly discussed economic term by both researchers and policy-makers. Foreign expertise provides various economic benefits to the host countries through improving existing production processes, increasing competitiveness, and reducing disparities in welfare. Foreign direct investment flows could be influenced by several institutional, economic and political factors. This paper aims to check up on the empirical relation between FDI and these factors in a panel of 12 countries for the 2002-2015 time period. In analysis, we employed an empirical method that considers cross-sectional dependence. Therefore, we explored long-term relations between variables through an estimation approach using Westerlund (2008) Durbin Hausman cointegration method and AMG estimator after unit root tests of variables. Empirical results clarify a positive connection between FDI and governance factors for some countries in the panel.
\end{abstract}

\section{INTRODUCTION}

The liberalization of capital movement, which began in the 1980 s, has gained momentum in the world. From the beginning of the 1980's onwards, liberal economic policies in the world have led to a rise in FDI, a rise in market economy, and an increase in international production. The recent globalization phenomenon in the world economy has helped developing countries to meet the capital they need through FDI (Ekinci, 2011; Hor, 2016).

The globalization process in the world has removed the borders between countries and obliged them to tie up with the world. As a consequence of augmenting globalization inclination, free movement of capital among countries becomes the main topic of economic and political conversation. For the developing countries confronting the shortfall of capital, FDI becomes the most effective way of eliminating undercapitalization.

Most fundamental characteristic of the trend towards globalization lately has been the escalated significancy of FDI around the world (Daude \& Stein, 2007; Phyoe, 2015). Be- cause, FDI has many positive impacts on employment, technological transfer, and eventually on the economic progress and growth of the host region. Within this scope, the source of FDI, its place of destination and its impacts on the country have been a subject matter of ongoing attention (Madani, 2017; Saidi, Ochi, \& Ghadri, 2013). Different from those, the endogenous growth theory, suggests FDI can encourage economic growth in emerging markets (Alemu, 2003; Lynn, 2014). For success in line with this purpose, the policies are rebuilt perpetually for making it available for the enterprisers to make investment. Some counties are enviable in encouraging FDI flows. However, some have confronted troubles in encouraging FDI (Zeshan \& Talat, 2014).

In recent times, the int'l development discussion and diplomatic expressions are interested in the notion of better governance, which became a prominent driver for the effective running of markets, thus, for the encouragement of FDI. Actually, govts searching to encourage FDI should create a more favourable climate for multilateral ventures (Saidi et al., 2013).

${ }^{*}$ corresponding author: Kivanç Altintaş

†email: kivancaltintas@gmail.com 
The economic boost of a country is also affected by the govt's decisions and its implementations as social, economical, juristicial and moral grounds. There are six components of governance procedure defined as governance indicators (Kaufmann, Kraay, \& Mastruzzi, 2011). These are the six elements of governance indicators: Accountability and voice, Political Stability and Absence of Violence, Government Effectiveness, Regulatory Quality, Rule of Law and finally Control of Corruption.

Primary aim of this work is to analyze the impact of governance factors on FDI stocks for 14 years between 2002 and 2015, including 12 countries. In this direction, firstly, information about governance/institutional issues and FDI is presented, and after that interactions of these two factors have been attempted to be explained. Secondly, the literature review that was summed up with previous papers is given. In the third part, the data set and method used during the econometric analysis of the study are introduced and empirical findings are presented in the subsequent fourth part. Finally, in the conclusion section, the study is briely assessed.

\section{LITERATURE REVIEW}

Saidi et al. (2013) analyze the relationship between governance factors and FDI. For this, they put 20 countries in their study including the years 1998-2011. They find positive correlation between FDI and some governance factors (quality of regulation and political stability). Also, Bellos and Subasat (2012) analyzed the same factors for some Latin countries and they found that good governance influences the FDI positively.

Sanchez-Robles and Bengoa-Calvo (2002) analyzed the link between FDI and economic freedom in 18 different Latin American countries between 1970 and 1999. According to the results obtained in this study by using panel data analysis method, economic freedom affects the FDI positively. Gastanaga, Nugent, and Pashamova (1998), investigated the relationship between several political factors and FDI in lows. He inds that lower corruption is related to higher FDI in lows. Yet he states that his indings are not always passable, because he considers 22 emerging markets in his work, it's relatively a small country specimen.

Méon and Sekkat (2004) investigated the impact of corporate quality on exports of manufactured goods and incoming FDI in the MENA countries. They found that a high level of corruption and poor bureaucracy affect the decision of multinational enterprises to invest abroad negatively.

Samimi and Ariani (2010) examined the effect of a good quality governance on FDI lows. They use yearly data for 16 countries in the MENA during the period from 2002-2007. They showed that the three governance factors are follows: control of corruption, rule of law and political sta-bility which have a positive in luence on the entry of FDI for the MENA region. Also, Tarek and Ahmed (2013) investigated the impact of governance indicators on the attractiveness of FDI in eleven countries in the MENA region during the period 1996-2014, using a random effects model. They found that the four governance variables named; freedom of speech and responsibility, the functioning of the state, the quality of regulation and the rule of law are positively related with to entry of FDI.

On the contrary, in some studies it has been concluded that there is a negative relationship between FDI and global governance indicators. According to Paniagua and Sapena (2014) study, using the data of 161 countries between the years 2003 and 2010, it is concluded that the potential to at-tract FDI decreases as the legal rights and democracy power increase in the country. This conclusion can be attributed to the fact that the democratic movements in the developed countries have directed workers towards unionization, and therefore the increase in wages and in lation is a negative situation for the countries that bring FDI. Additively, Wang and Swain (1997) in their study indicate that political stabil-ity in luences the FDI lows negatively. Political stability damages the job environment and for this reason decrease the FDI lows.

\section{METHODOLOGY}

\section{DATA SET/ECONOMETRIC MODEL}

In this study, which aims to determine the effect of countries' governance performance on foreign direct investments by means of panel data analysis, econometric analysis is carried out using 14-year series covering 12 countries from 2002 to 2015. Countries subject to our research are; China, Italy, South Korea, United States, France, South Africa, Netherlands, Spain, Turkey, United Kingdom, Japan and India. For the amount of FDI in the econometric analysis, the FDI data set is taken from the World Investment Report data sheets compiled by the United Nations Conference on Trade and Development (UNCTAD). A comparison of countries' managerial performance based on speci ic indices is taken from the World Bank's World Governance Indicators (WGI) 2017 data-set. The six mentioned indices are subjected to the principle component analysis method and thus we can get one index only GOVINDEX. In the study, some macroeconomic indicators are included as control variables in the econometric analysis. These variables are the Gross Domestic Product (GDP) and Trade Opennes 
(OPEN). The data for these two variables are gained from the World Bank's WDI 2017 dataset. Series are logarithmically transformed and subjected to empirical testing with the help of Eviews 8, Gauss 10 and STATA 11 software pro- grams. The model in which the effects of governance performances of countries on foreign direct investment are estimated using the panel data method is shown in Equation 1.

$$
L N F D I_{i t}=\alpha_{i t}+\beta_{1 i} L N G O V I N D E X_{t}+\beta_{2 i} L N G D P_{t}+\beta_{3 i} L N O P E N_{t}+\varepsilon_{i t}
$$

The term $i$ in Equation 1 refers to countries with crosssectional units, time dimension is $t$ and $\alpha$ and $\beta$ are longterm coef icients. Before determining the existence of a long-term relationship among the variables included in the estimation model, it is necessary to apply some pre-tests to the series to be used in the analysis and to determine appropriate methods according to these test results. The irst test is the horizontal section dependency test, while the second one tests the homogeneity of the long-term coef icients of the variables.

\section{EMPIRICAL RESULTS \& DISCUSSION}

In the panel data analysis, Breusch and Pagan (1980) and Pesaran (2004) $\mathrm{CD}_{\mathrm{LM}}$ tests for testing Cross Section Dependency (CD), and Pesaran, Ullah, and Yamagata (2008) improved the bias-adjusted CD test. Which of these methods will be used is determined by the number of coun- tries with the cross-section and period length. $\mathrm{CD}_{\mathrm{LM} 1}$ and $\mathrm{CD}_{\mathrm{LM} 2}$ should be preferred if the period length is bigger than the number of cross-sectional units; otherwise the Pesaran (2004)'s CD $_{\mathrm{LM}}$ method should be preferred. The bias adjusted CD test is a method to test the cross-section dependency without requiring such a condition. In this study, $t$ is a 14-year time period between 2002-2015, and $t$ is time dimension larger than $i$, which is the cross-sectional dimension, since 12 countries are analyzed.

Breusch and Pagan (1980) developed another method that can be used in samples where the cross- sectional dimension is large as well as the time dimension, although the $L M$ test is a method that can be used in models where the cross section units are relatively small compared to the time dimension. $\mathrm{CD}_{\mathrm{LM} 1}$ statistics of Breusch and Pagan (1980) LM horizontal section dependency test and Pesaran (2004) $\mathrm{CD}_{\mathrm{LM} 2}$ statistics are calculated as follows (Pesaran, 2004).

$$
C D_{L M 1}=T \sum_{i=1}^{N-1} \sum_{i=i+1}^{N} \hat{\rho}_{i j}^{2}
$$

TABLE 1. $C D$ and homogeneity tests

\begin{tabular}{lcc}
\hline \hline Tests & Statistics & Probability Value \\
\hline \hline$C D_{L M 1}$ & 156.382 & 0.000 \\
$C D_{L M 2}$ & 7.867 & 0.000 \\
$C D_{L M}$ & -2.618 & 0.004 \\
$L M_{a d j}$ & 6.703 & 0.000 \\
$\tilde{\Delta}$ & -3.464 & 1.000 \\
$\tilde{\Delta}_{a d j}$ & -4.099 & 1.000 \\
\hline \hline
\end{tabular}

$$
C D_{L M 2}=\sqrt{\frac{1}{N(N-1)}} \sum_{i=1}^{N-1} \sum_{i=i+1}^{N}\left(T \hat{\rho}_{i j}^{2}-1\right)
$$

$C D$ and homogeneity test results are given in Table 1 . The fact that the time dimension is bigger than the cross-section size in this study indicates that the findings of the methods for testing the cross-section dependency need to be examined for $C D_{L M 1}, C D_{L M 2}$ and $L M_{a d j}$. In this direction, when we look at the results of three methods $\left(C D_{L M 1}, C D_{L M 2}\right.$ and $L M_{a d j}$ ), the null hypothesis examining the cross-section de- pendency is rejected. In this way, alternative hypothesis is accepted. It means that there's $C D$ between these countries. Another preliminary test in this panel data analysis is to decide whether the slope coefficient is homogeneous or heterogeneous. The Delta test $(\Delta)$ used for this purpose was developed by Pesaran and Yamagata (2008). In the null hypothesis, the homogeneity of the slope coefficient is tested 
and heterogeneous in the alternative hypothesis. According to this method, it is more appropriate to interpret $\Delta$ in case of large scale panel and $\Delta_{a d j}$ in small scale panel. Since this study is conducted over a small panel of 12 countries, the
$\Delta_{\text {adj }}$ statistic should be interpreted. If the probability value of $\Delta_{a d j}$ is bigger than 0.05 at the $5 \%$ significance level, the rejection of the null hypothesis and the slope coefficient of the panel are homogeneous.

$$
\hat{\Delta}=\sqrt{N}\left(\frac{N^{-1} \tilde{S}-k}{\sqrt{2 k}}\right) \hat{\Delta}_{a d j}=\sqrt{N}\left(\frac{N^{-1} \tilde{S}-E\left(\tilde{Z}_{i T}\right)}{\sqrt{\operatorname{var} \tilde{Z}_{i T}}}\right)
$$

According to homogeneity test, as it is seen in the Table 2, null hypothesis is rejected and alternative hypothesis is accepted both for $\Delta$ and $\Delta_{a d j}$. It means that the slope coefficient is homogeneous.

After the cross-section dependency and homogeneity tests, the series have to be subjected to the stationarity test. The presence of $C D$ between countries makes it necessary to use $2^{\text {nd }}$ generation panel unit root tests. In this study, Pesaran (2007) 's CIPS and Cross-sectionally Augmented Dickey Fuller (CADF) statistics and Hadri and Kurozumi (2012) unit root tests are used to test for stationarity.

TABLE 2. CADF test results

\begin{tabular}{clllclll}
\hline \hline $\begin{array}{c}\text { IFDI } \\
\text { (Intercept) }\end{array}$ & $\begin{array}{l}\text { IFDI } \\
\text { (Intercept- } \\
\text { Trend) }\end{array}$ & $\begin{array}{l}\text { IINDEX } \\
\text { (Intercept) }\end{array}$ & $\begin{array}{l}\text { IINDEX } \\
\text { (Intercept- } \\
\text { Trend) }\end{array}$ & $\begin{array}{c}\text { IINDEX } \\
\text { (Intercept-Trend) }\end{array}$ & $\begin{array}{l}\text { lOPEN } \\
\text { (Intercept- } \\
\text { Trend) }\end{array}$ & $\begin{array}{l}\text { IGDP } \\
\text { (Intercept) }\end{array}$ & $\begin{array}{l}\text { IGDP } \\
\text { (Intercept- } \\
\text { Trend) }\end{array}$ \\
\hline$-1.17(1)$ & $-0.859(1)$ & $-2.751(1)$ & $-2.364(1)$ & $-2.279(2)$ & $-1.729(2)$ & $-1.038(1)$ & $-0.965(1)$ \\
$-1.08(2)$ & $0.041(2)$ & $-1.671(1)$ & $-2.037(1)$ & $-1.730(1)$ & $-0.325(2)$ & $-1.102(1)$ & $-1.492(1)$ \\
$-1.75(1)$ & $-1.258(1)$ & $-5.179(2)$ & $-1.594(2)$ & $-2.321(1)$ & $-1.895(1)$ & $-0.820(1)$ & $0.988(2)$ \\
$-3.39(1)$ & $-2.677(1)$ & $-3.787(1)$ & $-5.206(1)$ & $-1.346(2)$ & $-1.544(2)$ & $-4.375(2)$ & $-12.476(2)$ \\
$-3.51(1)$ & $-1.915(2)$ & $-0.414(1)$ & $-0.687(1)$ & $0.571(2)$ & $0.063(2)$ & $-4.255(2)$ & $-1.442(1)$ \\
$-3.26(1)$ & $-7.229(2)$ & $-0.455(1)$ & $-0.511(1)$ & $-1.376(1)$ & $-1.504(1)$ & $-3.248(2)$ & $-1.323(1)$ \\
$-2.14(1)$ & $-23.963(2)$ & $-1.962(2)$ & $-0.771(2)$ & $-1.352(2)$ & $2.986(2)$ & $-1.703(1)$ & $-1.145(1)$ \\
$-2.96(1)$ & $-1.401(2)$ & $-2.587(1)$ & $-2.311(1)$ & $0.325(2)$ & $-13.931(2)$ & $-1.653(1)$ & $-0.870(1)$ \\
$-3.65(1)$ & $-1.867(2)$ & $-0.509(1)$ & $-0.602(1)$ & $-1.802(1)$ & $-2.096(1)$ & $-2.722(1)$ & $-2.956(2)$ \\
$-3.81(1)$ & $-2.981(1)$ & $-2.415(1)$ & $-3.001(1)$ & $-1.985(1)$ & $-1.737(1)$ & $-2.000(1)$ & $-2.597(1)$ \\
$-1.93(1)$ & $-1.114(1)$ & $-0.414(1)$ & $-0.687(1)$ & $-2.309(2)$ & $-1.341(2)$ & $-1.241(1)$ & $-1.490(1)$ \\
$-1.48(1)$ & $-1.797(1)$ & $-1.642(1)$ & $-1.822(1)$ & $-1.347(1)$ & $-2.685(1)$ & $-1.534(1)$ & $-2.456(1)$ \\
\hline \hline
\end{tabular}

Note: Values in parentheses give the maximum delay length for each country

CADF a $2^{\text {nd }}$ generation unit root test used under crosssection dependency, performs stationarity tests for each country in the panel. In the case of Pesaran (2007) crosssectionally augmented IPS, CIPS statistical analysis, the panel is considered as a whole and the unit root existence is investigated by averaging. The Pesaran (2007) critical table values of the CADF statistic that a series provides for the stationarity condition for each country will be determined as the result of comparison. Similarly, the stationarity of the relevant variable for an entire panel is determined by comparing the CIPS statistics with the Pesaran (2007) critical table values. If the obtained CADF statistics are biggerthan the Pesaran (2007) critical table values, the null hypothesis that includes unit root in each country is accepted. Thus, for some of the countries in the panel, the stationarity con- dition will be accepted, but not for the others. If the CIPS statistic, which is an average value for the panel, is greater than the Pesaran (2007) Table 3 value, it can be assumed that the null hypothesis is that the panel contains whole unit root and the panel is not stable.

Hadri and Kurozumi (2012)indicate that the null hypothesis series is stationary in the unit root test, even though the null hypothesis variable is not static in the CIPS test. In the Hadri and Kurozumi (2012) unit root test, it is necessary that the probability value at the $95 \%$ significance level is greater than $0.05 \%$ in order to be able to deduce that the series are stationary. The results of the CADF test are also shown in 2 because this method calculates the results for the fixed and fixed-trending series of the series, and the CADF test uses the delay lengths for each country. 
Since the slope coefficients are homogeneous according to the homogeneity test result, the CIPS statistic which gives the average value of the panel to interpret the unit root exis- tence should be used instead of the CADF statistics. Critical values of CIPS test are obtained from Pesaran (2007) study and findings of unit root tests are presented in 3.

TABLE 3. Unit root test

\begin{tabular}{ccccccc}
\hline \hline Variables & $\begin{array}{c}\text { CIPS } \\
\text { (Intercept) }\end{array}$ & $\begin{array}{c}\text { CIPS } \\
\text { (Intercept-Trend) }\end{array}$ & $\begin{array}{c}\boldsymbol{Z}_{\boldsymbol{A}}^{\boldsymbol{S P C}} \\
\text { (Intercept) }\end{array}$ & $\begin{array}{c}\boldsymbol{Z}_{\boldsymbol{A}}^{L A} \\
\text { (Intercept) }\end{array}$ & $\begin{array}{c}\boldsymbol{Z}_{\boldsymbol{A}}^{\boldsymbol{S} P C} \\
\text { (Intercept-Trend) }\end{array}$ & $\begin{array}{c}\boldsymbol{Z}_{\boldsymbol{A}}^{L A} \\
\text { (Intercept-Trend) }\end{array}$ \\
\hline IFDI & -1.986 & -2.760 & 0.1142 & 3.0530 & -1.5003 & -2.5215 \\
& & & $(0.4546)$ & $(0.0011)$ & $(0.9332)$ & $(0.9942)$ \\
IINDEX & -1.617 & -2.114 & 0.4748 & 10.3164 & -0.1583 & 2.0209 \\
& & & $(0.3175)$ & $(0.0000)$ & $(0.5629)$ & $(0.0216)$ \\
IOPEN & -1.148 & -1.313 & -1.4633 & -1.4189 & 2.7010 & 1.3522 \\
& & & $(0.9283)$ & $(0.9220)$ & $(0.0035)$ & $(0.0882)$ \\
IGDP & -1.777 & -2.594 & 2.7002 & 2.4154 & 1.8601 & 0.3706 \\
& & & $(0.0035)$ & $(0.0079)$ & $(0.0314)$ & $(0.3555)$ \\
\hline \hline
\end{tabular}

Note: Probability values are given in parentheses

The CIPS statistics for the variables IFDI, IINDEX, IOPEN and IGDP are obtained as a unit root in the intercept version of the series. Likewise, since the intercept-trend CIPS values of all four series are bigger than the critical table value of Pesaran (2007), the null hypothesis is accepted and it is decided that the series are not stationary and series include unit root.

Hadri and Kurozumi (2012), designed panel data analysis of Hadri unit root test used in time series analysis. In the Hadri and Kurozumi (2012) unit root test, the null hypothesis series is stationary, while the alternative hypothesis is not stationary. In this method, the appropriate delay length of each country obtained by the CADF test is required in order to derive the test statistic. From Table 4, it can be seen that the intercept version of the foreign direct investment variable is not stationary at the level and contains unit root, while the intercept-trend version is stationary at the level. Regarding the variance of governance indicators, it appears that both the intercept and the intercept-trend versions of the series are not stationary in level and contain unit roots. In the trade openness variable, the intercept version is stationary at the level, and the intercept-trend version contains the unit root at the level without stationarity. Finally, when we look at the gross domestic product variable, it is understood that the intercept version of the series is not stationary at the level but contains unit roots, and in the intercepttrend version it is stationary at the level and does not contain unit roots.

Following the determination of the stationary level of the series, the existence of a long-run interaction between the series should be investigated in the next step with methods that will be appropriate to the unit root results. The Durbin-Hausman cointegration test, developed by Westerlund (2008), tests whether there is a long-term interactions between the series in which cross-section dependency is present.

$$
\begin{gathered}
D H_{g}=\sum_{i=1}^{n} \hat{S}_{i}\left(\tilde{\theta}_{i}-\hat{\theta}_{i}\right)^{2} \sum_{t=2}^{T} \hat{e}_{i t-1}^{2} \\
D H_{p}=\hat{S}_{n}(\tilde{\theta}-\hat{\theta})^{2} \sum_{i=1}^{n} \sum_{t=2}^{T} \hat{e}_{i t-1}^{2}
\end{gathered}
$$

This test calculates two different statistics for the panel $D H_{\mathrm{p}}$ and $\mathrm{DH}_{\mathrm{g}}$ for the group. For both statistics it is tested that there is no cointegration between the variables in the null hypothesis. According to the panel statistical $D H_{\mathrm{p}}$, rejection of the null hypothesis implies that there is a cointegration for the whole of the panel, whereas for the $D H_{\mathrm{g}}$ representing the group statistic, the rejection of the null hypoth- esis implies a long-term relationship in some of the panelconstituting countries (Westerlund, 2008). According to this method, the rejection of the null hypothesis and the deduction of the existence of the cointegration relation specified in the alternative hypothesis requires that the group and panel statistic values are larger than the critical table value (Westerlund, 2008). 
TABLE 4. Westerlund (2008) panel co-integration test results

\begin{tabular}{lll}
\hline \hline & $\boldsymbol{D H}_{\mathbf{g}}$ Group Stat & $\begin{array}{l}\boldsymbol{D} \boldsymbol{H}_{\mathbf{p}} \text { Panel } \\
\text { Stat }\end{array}$ \\
\hline Statistics & -1.185 & -2.450 \\
Probability value & $(0.118)$ & $(0.007)$ \\
Critical values & & \\
$\% 1$ & 2.33 & 2.33 \\
$\% 5$ & 1.645 & 1.645 \\
$\% 10$ & 1.28 & 1.28 \\
Results & No co-integration & $\begin{array}{l}\text { There's co- } \\
\text { integration }\end{array}$ \\
& & \\
\hline \hline
\end{tabular}

Westerlund (2008) null hypothesis was accepted because the Durbin-Hausman panel cointegration test results show that the group statistic is smaller than the critical table value, so that no long-run interactions were found in some countries. However, it is seen that the panel statistic is bigger than the critical table values. The alternative hypothesis was accepted by rejecting the null hypothesis that there is no cointegration relation between variables according to the panel statistical result evaluating the panel as a whole. In this respect, cointegration test results show that there's a long-run interaction between foreign direct investments and the governance indicators for the panel as a whole. After deciding that there is a long-run interactions between series, long-run parameters will estimate at the next stage. In this direction, Eberhardt and Bond (2009), Eberhardt and Teal (2010) Augmented Mean Group (AMG) Estimator was used in order to obtain individual long term coefficients for each country. Estimating the long term coefficient with the help of AMG method requires following empirical models.

$$
\begin{gathered}
y_{i t}=\beta_{i}^{\prime} x_{i t}+u_{i t} \\
u_{i t}=\alpha_{i}+\lambda_{i}^{\prime} f_{t}+\varepsilon_{i t} \\
x_{m i t}=\pi_{m i}+\delta_{m i}^{\prime} g_{m t}+\rho_{1 m i} f_{1 m t}+\ldots+\rho_{n m i} f_{n m t}+\vartheta_{m i t} \\
f_{t}=6^{\prime} f_{t-1}+\epsilon_{t} \\
g_{t}=k^{\prime} g_{t-1}+\epsilon_{t}
\end{gathered}
$$

The results of the AMG estimator for this study, in which the effect of countries' governance indicators on foreign direct investment is searched, are shown in Table 5. According to these results, in the whole panel, it is understood that governance indicators have a statistically significant effect on foreign direct investments with positive direction and 95\% significance level. A 1\% increase in the governance indicator index increases foreign direct investment by $0.30 \%$. A $1 \%$ increase in GDP would increase foreign direct investment by $0.95 \%$ at $1 \%$ significance level. Since the $t$-statistic of the tradel openness variable is low, it is meaningless and uninterpreted.

TABLE 5. Long term coefficient estimation with AMG method

\begin{tabular}{lccc}
\hline \hline & Coefficients & $\boldsymbol{t}$-Statistics & Probability Value \\
\hline IINDEX & $0.2990^{* *}$ & 2.01 & 0.045 \\
lGDP & $0.9544^{*}$ & 5.82 & 0.000 \\
lOPEN & -0.1494 & -0.87 & 0.386 \\
Intercept & $-14.50405^{*}$ & -2.97 & 0.003 \\
\hline \hline
\end{tabular}

Note: The signs $\left({ }^{*}\right),\left(^{* *}\right)$ and $\left({ }^{* * *}\right)$ represent significance of the $t$-statistics of the coefficients relative to the significance levels of $1 \%, 5 \%$ and $10 \%$ respectively.

\section{CONCLUSION}

This study, including the years 2002-2015, examines whether there is a long run cointegration between FDI and governance indicators for 12 countries. For this purpose, the existence of $C D$ and homogeneity are tested. Findings show that there is $C D$ in the sample and the countries 
have homogeneous characteristics. In this direction, econometric analyzes are based on second generation methods considering $C D$. Since the $2^{\text {nd }}$ generation unit root tests show that variables are stationary at different levels, the existence of a long-run interactions has been explored using cointegration methods that take account of stationarity at different levels. As a result of the Durbin-Hausman method, Westerlund (2008) found the existence of a longrun interactions and estimated long-run coefficients with the Eberhardt and Bond (2009) AMG method. The analysis shows that governance indicators affect foreign direct investment positively and statistically significant for the whole panel.

\section{REFERENCES}

Alemu, A. M. (2003). Quality of institutions and fdi in flow: Evidence from asian cconomies. Korea Review of International Studies, 1(1), 35-47.

Bellos, S., \& Subasat, T. (2012). Governance and foreign direct investment: A panel gravity model approach. International Review of Applied Economics, 26(3), 303-328. doi:https://doi.org/10.7764/laje.50.1.107

Breusch, T. S., \& Pagan, A. R. (1980). The lagrange multiplier test and its applications to model specification in econometrics. The Review of Economic Studies, 47(1), 239-253. doi:https://doi.org/10.2307/2297111

Daude, C., \& Stein, E. (2007). The quality of institutions and foreign direct investment. Economics \& Politics, 19(3), 317-344.

Eberhardt, M., \& Bond, S. (2009). Cross-section dependence in nonstationary panel models: A novel estimator. In the Nordic Econometrics Meeting. Lund, Sweden.

Eberhardt, M., \& Teal, F. (2010). Productivity analysis in global manufacturing production (Working paper). Department of Economics, University of Oxford, Oxford, UK.

Ekinci, A. (2011). Doğrudan yabancı yatırımların ekonomik büyüme ve istihdama etkisi: Türkiye uygulaması (1980-2010). Eskişehir Osmangazi Üniversitesi İktisadi ve İdari Bilimler Dergisi, 6(2), 71-96.

Gastanaga, V. M., Nugent, J. B., \& Pashamova, B. (1998). Host country reforms and fdi inflows: How much difference do they make? World development, 26(7), 1299-1314. doi:https://doi.org/10.1016/s0305-750x(98)00049-7

Hadri, K., \& Kurozumi, E. (2012). A simple panel stationarity test in the presence of serial correlation and a common factor. Economics Letters, 115(1), 31-34. doi:https://doi.org/10.1016/j.econlet.2011.11.036

Hor, C. (2016). Analysis of the impact of determinant factors on foreign direct investment in Cambodia: The ARDL bounds testing approach. Journal of Administrative and Business Studies, 2(4), 177-188. doi:https://doi.org/10.20474/jabs-2 .4 .4

Kaufmann, D., Kraay, A., \& Mastruzzi, M. (2011). The worldwide governance indicators: Methodology and analytical issues. Hague Journal on the Rule of Law, 3(2), 220-246. doi:https://doi.org/10.1017/s1876404511200046

Lynn, K. K. (2014). An analysis of the relationship between foreign trade and economic growth in Myanmar during 1990-2014. International Journal of Business and Administrative Studies, 1(4), 114-131. doi:\{https://doi.org/ \}$\{10.20469 /$ ijbas.10001-4\}

Madani, S. (2017). Economic evaluation of investment for oceanographic research by using cost benefit analysis (A case study of Iranian National Institute for Oceanography). International Journal of Business and Economic Affairs, 2(2), 85-90. doi:https://doi.org/10.24088/ijbea-2017-22001

Méon, P. -G., \& Sekkat, K. (2004). Does the quality of institutions limit the mena's integration in the world economy? The World Economy, 27(9), 1475-1498. doi:https://doi.org/10.1111/j.0378-5920.2004.00661.x

Paniagua, J., \& Sapena, J. (2014). Is FDI doing good? A golden rule for FDI ethics. Journal of Business Research, 67(5), 807-812. doi:https://doi.org/10.1016/j.jbusres.2013.11.049

Pesaran, M. (2004). General diagnostic tests for cross section dependence in panels (Working paper No. 1129). Institute for New Economic Thinking, University of Southern California, Los Angeles, CA.

Pesaran, M. (2007). A simple panel unit root test in the presence of cross-section dependence. Journal of applied econometrics, 22(2), 265-312. doi:https://doi.org/10.1002/jae.951

Pesaran, M., Ullah, A., \& Yamagata, T. (2008). A bias-adjusted lm test of error cross-section independence. The Econometrics Journal, 11(1), 105-127. doi:https://doi.org/10.1111/j.1368-423x.2007.00227.x

Pesaran, M., \& Yamagata, T. (2008). Testing slope homogeneity in large panels. Journal of Econometrics, 142(1), 50-93. doi:https://doi.org/10.1016/j.jeconom.2007.05.010 
Phyoe, E. E. (2015). The relationship between foreign direct investment and economic growth of selected ASEAN Countries. International Journal of Business and Administrative Studies, 1(4), 132-146. doi:https://doi.org/10.20469/ijbas.10002 $-4$

Saidi, Y., Ochi, A., \& Ghadri, H. (2013). Governance and FDI attractiveness: Some evidence from developing and developed countries. Global Journal of Management And Business Research, 13(6), 14-24.

Samimi, A. J., \& Ariani, F. (2010). Governance and FDI in MENA Region. Australian Journal of Basic and Applied Sciences, 4(10), 4880-4882.

Sanchez-Robles, B., \& Bengoa-Calvo, M. (2002). Foreign direct investment, economic freedom and growth: New evidence from latin-america (Working paper no No. 4-30). Universidad de Cantabria, Santander, Spain.

Tarek, B. A., \& Ahmed, Z. (2013). Governance and economic performance in developing countries: An empirical study. Journal of Economics Studies and Research, 2013(1), 1-14. doi:https://doi.org/10.5171/2013.390231

Wang, Z. Q., \& Swain, N. (1997). Determinants of inflow of foreign direct investment in Hungary and China: Timeseries approach. Journal of International Development, 9(5), 695-726. doi:\{https://doi.org/10.1002/\}\{(sici)1099 $-1328(199707) 9\}$

Westerlund, J. (2008). Panel cointegration tests of the fisher effect. Journal of Applied Econometrics, 23(2), 193-233. doi: https://doi.org/10.1002/jae.967

Zeshan, A., \& Talat, A. (2014). Impact of Governance Indicators on FDI Inflows: Empirical evidence from Pakistan. Caspian Journal of Applied Sciences Research, 3(9), 16-23. 